Z. klin. Chem. u. klin. Biochem.

7. Jg., S. 51-52, Januar 1969

\title{
Nieren-Clearance der Isoamylasen beim Menschen
}

\author{
VOn J. KAMARÝT \\ Aus dem Forschungsinstitut fïr Pädiatrie, Brno (CSSR) (Direktor: Prof. MUDr. Z. Brunecký, C. Sc.)
}

(Eingegangen am 27. September 1968)

\begin{abstract}
Die Clearance der Speichel-Amylasé beim normalen Menschen beträgt etwa dic Hälftc der Pankreas-Amylase-Clearance. Mit großer Wahrscheinlichkeit ist diese Differenz Folge der unterschiedlichen Molekülgröße der Isoamylasen, welche die Filtrations- sowie auch die Resorptions-Geschwindigkeit beeinflußt. Die maximale Nieren-Isoamylase-Ausscheidung liegt in den Nachmittagsstunden ohne Rücksicht auf die Diät und das Tages-Regime. Die angeführten Feststellungen kann man in der klinischen Diagnostik für die genauere Beurteilung der Glomerularmembran-Permeabilität oder in der Genetik für ein exaktes Studium der einzelnen Isoamylasen-Aktivitäten ausnützen.
\end{abstract}

\section{The renal clearence of isoamylases in man}

The clearance of salivary amylase is about onc half of the pancreatic amylase clearance in normal adults. The difference is most probably due to the difference in the molecular size of the two amylases, which affects both the filtration and the absorption rates. The maximal kidney excretion of isoamylases occurs around midday, irrespective of diet and daily routine. These results can be used in clinical diagnosis for a more exact cvaluation of glomerular membrane permeability, or for more exact genetic study of the several isoamylases activities.

a-Amylase ${ }^{1}$ ) wird in Speicheldrüsen und Pankreas produziert. Wegen der inkretorischen Tätigkeit beider Drüsengruppen ist die Enzymaktivität im Blut meßbar, aber trotz ihres Protein-Charakters ist es möglich, auch im Urin Amylase-Aktivität nachzuweisen. $\mathrm{Da}$ das Molekulargewicht von Amylase mit ungefähr 45000 im Vergleich zu dem anderer Proteine relativ niedrig ist, wird das Enzym leicht durch die Glomerula filtriert. Mit der Methode der Agar-Gel-Elektrophorese sowie mit anderen Methoden ist es möglich, im Blut und im Harn die Gesamtamylase-Aktivität in zwei Fraktionen Speichel- und Pankreas-Amylase zu trennen (1-6). Beim gesunden Menschen ist der SerumamylaseAktivitäts-Spiegel außerordentlich stabil (7). Vom genetischen Aspekt her ist es interessant, $\mathrm{da} B$ das Verhältnis von Speichel- und Pankreas-Amylase bei den einzelnen Probanden nur mäßig variiert und - wie wir schon früher gezeigt haben - bei monozygoten Zwillingen gleich ist (8).

In vorangegangenen Untersuchungen hat uns überrascht, $\mathrm{da} B$ dieses Verhältnis von Speichel- und Pankreas-Amylase im Serum, welches in der Regel 1:1 beträgt, in keiner Ubereinstimmung mit dem Verhältnis im Urin steht.

Wir haben daher die Nieren-Clearance der Gesamt-. amylase sowie der Speichel- und Pankreas-Amylase bei gesunden Erwachsenen bestimmt, um zu erkennen, ob nicht diese unsere vorläufige Feststellung eine gesetzliche Erscheinung darstellt.

\section{Material und Methoden}

Wir haben 10 gesunde Probanden, fünf Männer und fünf Frauen, im Alter von etwa 30 Jahren untersucht. Im Verlauf von 24 Stdn. wurde ihr Harn am Tage in dreistündlichen und während der Nacht in beliebigen Intervallen gesammelt. Die Entnahmen des gerinnenden Blutes sind im Verlauf des Versuches auf nur eine reduziert worden. Diät und Tages-Regime der untersuchten Personen waren normal.

1) Der Trivialname $\alpha$-Amylase wird hier gebraucht für das Enzym $\alpha$-1,4-glucan 4-glucanohydrolase (EC 3.2.1.1).
Zur Bestimmung der Gesamtamylase-Aktivität im Blutserum und auch im Harn haben wir die Methode nach STreer und Close (9) benützt. Die Amylase-Heterogenität wurde mit der schon früher publizierten, von uns modifizierten Methode der Agar-Gel-Elektrophorese bestimmt $(1,7)$. Als Maß der glomarulären Filtration diente dic Clearance des endogenen Kreatinins, welche parallel in allen Blut- und Harn-Proben bestimmt wurde.

\section{Ergebnisse}

Wir haben die Mittelwerte und Standardabweichungen von Gesamtamylase-Aktivitāt, Isoamylasen-Aktivitäten und Kreatinin-Clearance separat für die Gruppe der Frauen und Männer berechnet. Mit Rücksicht darauf, $\mathrm{da} B$ die Differenzen der Bestimmungswerte in beiden Gruppen nicht wesentlich waren, haben wir beide Gruppen vereinigt.

Die erste Tabelle zeigt die Mittelwerte mit Standardabweichungen der Gesamtamylase- und IsoamylasenAktivitäten im Serum und Harn. Daraus ist eine grundsätzliche Diskrepanz zwischen den beiden Serum- und Harn-Isoamylasen ersichtlich. Sehr deutlich erscheint diese Differenz auf der Abbildung, wo die Zymogramme der Serum- und Harn-Amylase mit der Registration der Enzymaktivitäten dokumentiert werden (Abb. 1).

Die Blutvolumina, die innerhalb des Nierendurchflusses von der Speichel- und Pankreas-Amylase gereinigt werden, sind in Abbildung 2 ersichtlich. Die Clearance der Speichel-Amylase beträgt $50 \%$ der Pankreas-Amylase-Clearance. Die letzte Kolonne sțellt die Kreatinin-Clearance dar, welche die glomeruläre

Tab. 1

Mittelwerte und Standard-Abweichung der Gesamtamylase- und Isoamylasen-Aktivitäten im Serum und Harn $(n=10)$

\begin{tabular}{|c|c|c|}
\hline $\begin{array}{l}\text { Serum-Amylase } \\
\text { Gesamt-Amylase } \\
\text { Speichel-Amylase } \\
\text { Pankreas-Amylase }\end{array}$ & $\begin{array}{c}\mathrm{E} / 100 \mathrm{ml} \\
21,8 \pm 5,4 \\
11,7 \pm 1,4 \\
10,1 \pm 1,4\end{array}$ & $\begin{array}{c}\% \\
53,5 \pm 6,4 \\
46,5 \pm 6,4\end{array}$ \\
\hline $\begin{array}{l}\text { Harn-Amylase } \\
\text { Gesamt-Amylase } \\
\text { Speichel-Amylase } \\
\text { Pankreas-Amylase }\end{array}$ & $\begin{array}{c}\text { E/24 Stdn. } \\
701,5 \pm 167,6 \\
238,0 \pm 38,6 \\
464,0 \pm 38,6\end{array}$ & $\begin{array}{l}33,9 \pm 5,5 \\
66,1 \pm 5,5\end{array}$ \\
\hline
\end{tabular}




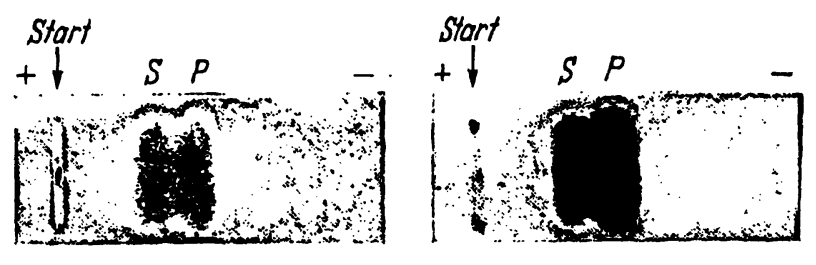

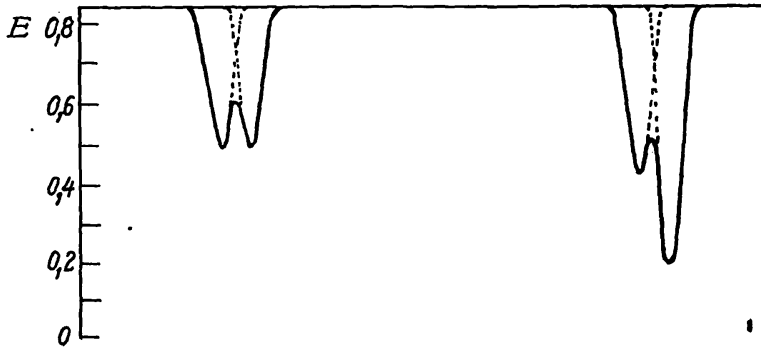

Abb. 1

Negative von Zymogrammen der Serum- und Harn-Amylase mit der Registration der Enzymaktivitäten bei einem gesunden Erwachsenen (Harn-Verdünnung $1: 3$ ). Jod-Stärke-Reaktion: Untergrund blau $(E=0,85)$, Aktivitätszonen hell (vgl. 1. c. (6))

Links: Serum Speichel-Amylase (S) $50,7 \%$, Pankreas-Amylase (P) $49,3 \%$ der Gesamtaktivität $(22,1 \mathrm{E} / 100 \mathrm{ml})$

Rechts: Harn. Speichel-Amylase (S) $36,8 \%$, Pankreas-Amylase (P) $63,2 \%$ der Gesamtaktivität

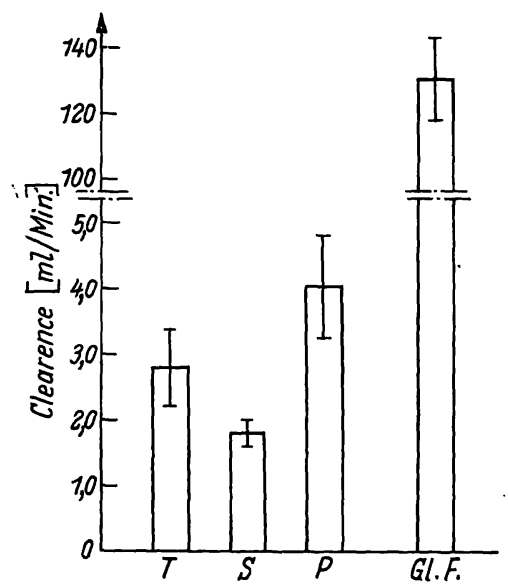

Abb. 2

Nieren-Clearance der Gesamtamylase (T), Speichel- (S) und PankreasAmylase $(P)$ und des Kreatinins (Gl. F). Mittelwerte mit Standardabweichungen $(\mathbf{n})=10)$

$$
\mathrm{C}(\mathrm{m} l / \mathrm{Min} .)=\frac{\mathrm{U}_{\mathrm{X}} \cdot \mathrm{V}}{\mathrm{P}_{\mathrm{X}}}
$$

Filtration repräsentiert. Die Clearance der Gesamtamylase ist dann $50 \mathrm{mal}$ niedriger als die Clearance des endogenen Kreatinins, sie beträgt nur $2 \%$ von dieser.

Die maximale Nieren-Ausscheidung der Isoamylasen beim gesunden Menschen liegt in den Nachmittagsstunden, und zwar ohne Rücksicht auf die Diät und das

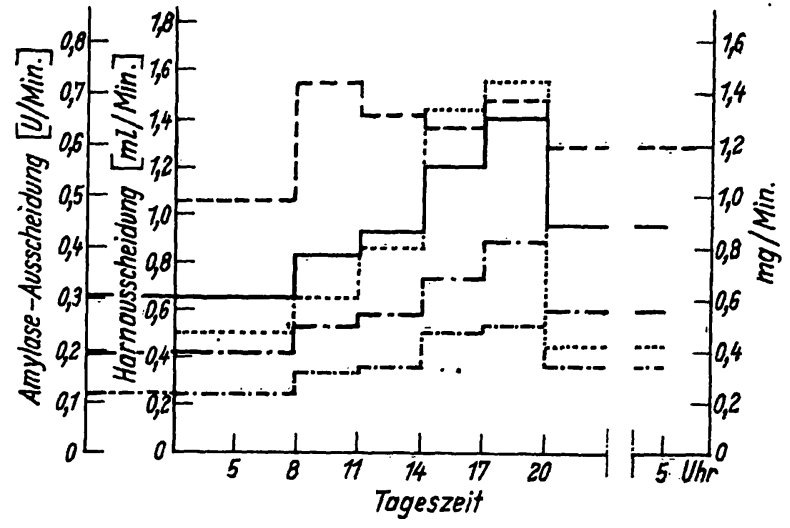

Abb. 3

Dynamik der Nieren-Ausscheidung der Gesamt-, Speichel- und Pankreas-Amylase innerhalb 24 Stdn. $(n=1)$

- Gesamtamylase E/Min.

-.-.-. Speichel-Amylase E/Min

....... Pankreas-Amylase E/Min.

. . - Kreatinin mg/Min.

Tages-Regime (Abb. 3). Aus den erwähnten Befunden, d. h. Nierenausscheidung der Speichel- und PankreasAmylase, ist es möglich, den Anteil der inkretorischen Tätigkeit der Speicheldrüsen und des Pankreas zu kalkulieren. Für die Speicheldrüsen beträgt dieser $1 \%$ und für das Pankreas $2 \%$.

\section{Diskussion}

Die unterschiedlichen Clearance-Werte der Spéichelund Pankreas-Amylase können als Folge der verschiedenen Molekulargewichte oder vielmeht als Unterschiede in der Molekülgröße erklärt werden. Die Kopplung der Speichel-Amylase an ein anderes Protein oder Substrat und eine dadurch verzögerte oder ganz unmögliche Filtration des so entstehenden Komplexes durch die Glomerularmembran kann man auch nicht ausschließen. Es ist aber auch die zweite Eventualität möglich, und zwar die beschleunigte Filtration der Pankreas-Amylase infolge teilweise verlaufender Degradation des ursprünglichen Enzymmoleküls im Kreislauf, ohne daß es zur Reduzierung der Gesamtaktivität des Enzyms kommt.

Die nächsten ausführlichen Studien, welche zur näheren Charakterisierung einiger Isoamylasen führen sollen, können auf Grund der in Funktionsproben ermittelten - Unterschiede mehr Klarheit in diese Problematik bringen.

\section{Literatur}

1. Kaxarýr, J. und R. Laxova, Humangenetik, 1, 579 (1965). 2. Aw, S. E., Nature, London 209, 298 (1966). - 3. BERK, J. E., S. Hayashi, R. L. Searcy und N. C. Hightower jr., Amer. J. Dig. Dis. 11, 695 (1966). - 4. Josephi, R. R., E. Olivero und N. Ressler, Gastroenterology, 51, 377 (1966). - 5. Oger, A. und
L. Bischops, Clin. chim. Acta, Amsterdam 13, 670 (1966). 6. KamarÝt, J., diese Z. 6, 96 (1968). - 7. KamarÝ'́, J., Vnitřní lékařství, im Druck. - 8. Kamaŕ́t, J. und R. LAXợ̂́, Humangenetik, 3, 41 (1966). - 9. Street, H. V. und J. R. Close, Clin. chim. Acta, Amsterdam 1, 256 (1956).
RNDr. Jaromír Kamarýt, C. Sc Forschungsinstitut für Pädiatrie Cernopolni 9

Brno, Tschechoslowakei 